\title{
Influence of KISS1 gene polymorphisms on the risk of polycystic ovary syndrome and its associated variables, in Saudi women
}

Maha H. Daghestani ${ }^{1}$, Mazin H. Daghestani ${ }^{2}$, Mamoon Daghistani ${ }^{3}$, Khushboo Ambreen ${ }^{4}$, Fadwa S. Albalawi ${ }^{1}$, Lina M. AlNeghery ${ }^{5}$ and Arjumand S. Warsy ${ }^{6^{*}}$

\begin{abstract}
Background: Polycystic ovary syndrome (PCOS) is a complex multifactorial disorder, affecting millions of women worldwide. The role of genetic polymorphisms of the KISS1 gene on the development of PCOS is still obscure. This study was designed to investigate the probable influence of KISS1 gene polymorphisms on PCOS and its associated variables: BMI, waist-hip ratio, kisspeptin, LH, FSH, and LH-FSH ratio.

Methods: The study comprised 104 PCOS women and 109 controls, with age ranging from 19 to 36 years. BMI, waist-hip ratio, and circulating levels of kisspeptin, LH, and FSH were measured. DNA was extracted, and genotyping of the KISS1 gene was carried out by nucleotide sequencing. The PCOS-associated variables were analyzed in different genotypes of single nucleotide polymorphisms (SNPS) of the KISS1 gene.

Results: The values of waist-hip ratio (WHR), LH, and LH-FSH ratio were significantly higher in PCOS women than controls. BMI, kisspeptin, and FSH levels exhibited no significant difference between the groups. Six novel SNPs of KISS1 gene were identified. Three: rs372790354G > A, rs12998G > A, and rs35431622A > T were investigated. Among these SNPs, the genotype and allele frequencies of rs372790354 showed significant association with PCOS (GA: $p=$ 0.018, AA: $p=0.022$, mutant allele-A: $p=0.021$ ) and the $\mathrm{G}$ allele was protective. The values of LH, kisspeptin, and WHR of PCOS women were significantly influenced $(p<0.05)$ by the AA genotype of rs372790354. The other two SNPs rs12998G > A and rs35431622A > T revealed no significant influence on PCOS and associated variables. Haplotypes were constructed, but there was no significant difference between the patients and controls.

Conclusion: In conclusion, this is the first study, which reports a significant influence of KISSI gene polymorphism (rs372790354G > A) on PCOS and its associated variables. However, more extensive research is necessary to confirm these findings.
\end{abstract}

Keywords: Polycystic ovary syndrome, KISS1 gene polymorphisms, Kisspeptin, LH, FSH, Waist-hip ratio

\footnotetext{
*Correspondence: aswarsy@gmail.com

${ }^{6}$ Central Laboratory, Female Center for Scientific and Medical Colleges, King Saud University, Riyadh, Saudi Arabia

Full list of author information is available at the end of the article
}

(c) The Author(s). 2020 Open Access This article is licensed under a Creative Commons Attribution 4.0 International License, which permits use, sharing, adaptation, distribution and reproduction in any medium or format, as long as you give appropriate credit to the original author(s) and the source, provide a link to the Creative Commons licence, and indicate if changes were made. The images or other third party material in this article are included in the article's Creative Commons licence, unless indicated otherwise in a credit line to the material. If material is not included in the article's Creative Commons licence and your intended use is not permitted by statutory regulation or exceeds the permitted use, you will need to obtain permission directly from the copyright holder. To view a copy of this licence, visit http://creativecommons.org/licenses/by/4.0/. The Creative Commons Public Domain Dedication waiver (http://creativecommons.org/publicdomain/zero/1.0/) applies to the data made available in this article, unless otherwise stated in a credit line to the data. 


\section{Background}

Polycystic ovary syndrome (PCOS) is one of the notable common health concerns in the female society of reproductive age ranging from 12 to 45 years with a highly variable prevalence rate of 2.2 to $26 \%$ in different ethnic groups [1]. It is a complex endocrine disorder characterized by chronic anovulation, hyperandrogenism, and polycystic ovarian morphology and associated primary clinical manifestations of irregular or missed periods, and excessive hair growth on the face and body [2]. In addition to these endocrinal factors and its related health complications, the complex etiology of PCOS is also influenced by the involvement of genetic, metabolic, and environmental factors [3].

In recent years, considerable research efforts have been made towards understanding the multifactorial etiology of PCOS. In this regard, genetic understanding of this disease in terms of hypothalamic-pituitarygonadal (HPG) axis associated genetic factors, has received considerable attention by the researchers [4].

Many previous studies have explored mutations in the HPG axis linked various genes such as KISS1, GPR54 receptor, GnRHR, LHR and FSHR, for the development of PCOS in the adult female population [5-7]. Among these genes, KISS1 has emerged as one of the candidate genes contributing to a regulatory role in the female reproductive system with an essential function in gonadotropin secretion of the HPG axis [8]. Some single nucleotide polymorphisms (SNPs) in the KISS1 gene are found to disrupt the healthy functioning of the female reproductive system through disturbing the HPG axis and are postulated to play an essential role in PCOS etiopathogenesis [5, 9].

The effects of KISSI gene polymorphisms on susceptibility to PCOS have been investigated in two previous studies $[9,10]$. However, until now, no adequately powered study is available in the literature, which confidently reveals the role of any relevant polymorphism of the KISS1 gene in PCOS pathogenesis.

Biochemically, ovarian dysfunction of PCOS is reflected in the excessive production of luteinizing hormone (LH) and a normal or low level of folliclestimulating hormone (FSH) from the anterior pituitary [11]. Kisspeptins are neuropeptides of different amino acid lengths (Kp-54, Kp-14, Kp-13, and Kp-10), encoded by the KISS1 gene, and unveils a vital regulatory role in the function of the HPG-axis, by utilizing G proteincoupled receptor known as GPR54 [12]. The major pathway of kisspeptin is the direct action on GnRH neurons to release $\mathrm{GnRH}$ into the portal circulation, which in turn induces the stimulatory activity of LH and FSH with the release of androgens [13]. Hence, the evaluation of the circulating levels of kisspeptin, LH, and FSH in susceptible women may be of importance in understanding the multifactorial etiology of PCOS.

Likewise, elevated values of body mass index (BMI) and waist-hip ratio (WHR) are considered as conventional anthropometric markers for the feature of obesity. They are proved to be linked with PCOS risk by directly creating disturbances in metabolic as well as endocrine system $[14,15]$. Many previous reports also emphasize the significance of BMI and waist-hip ratio as the markers of obesity, having responsibility for the comorbidity events of PCOS [16-18].

Hence, KISS1 gene polymorphisms, kisspeptin, LH, FSH, BMI, and waist-hip ratio are the essential interlinking factors that exert their influence on the expression of PCOS. The current study investigates the values of BMI, waist-hip ratio, and the blood levels of kisspeptin, $\mathrm{LH}, \mathrm{FSH}$, and the ratio of LH-FSH, in PCOS patients and controls. In an attempt to determine the influence of the KISS1 gene polymorphisms on the development of PCOS, the study assesses the genotype and allele frequencies of SNPs of the KISS1 gene for both study groups. Furthermore, we have attempted to demonstrate the possible influence of the KISS1 gene polymorphisms on PCOS associated endocrine and obesity-linked variables (kisspeptin, LH, FSH, LH-FSH ratio BMI, and waist-hip ratio).

\section{Methods}

\section{Study subjects}

The subjects of this present case-control study consisted of 104 women with well-characterized manifestations of PCOS and 109 control healthy women having no clinical history of PCOS. The study was approved by the Ethical Committee of the Institutional Review Board (IRB), Umm Al-Qura University, Makkah, Saudi Arabia (IRB No. 235). Study participants with an age range of 19-36 years, were recruited from different private hospitals of Makkah, Kingdom of Saudi Arabia.

Enrolled PCOS patients were newly diagnosed, and the criteria for the diagnosis of the PCOS patients was based on two of the three following features, according to Rotterdam 2003 criteria: (I) oligomenorrhea (menstrual period length greater than 35 days) or amenorrhea (menstrual period absent for six months), (II) clinical and/or biochemical signs of hyperandrogenism, (III) polycystic ovaries morphology as seen on ultrasound (at least one ovary contained $>12$ follicles measuring $2-9 \mathrm{~mm}$ in diameter and/or increased ovarian volume of at least 10 ml) [19].

Patients having other reasons, of hyperandrogenism or menstrual irregularity such as Cushing's syndrome, prolactinoma, and congenital adrenal hyperplasia were excluded. Pregnancy cases and women with the first postpartum year were also not included in our study. 
Patients having received any kind of hormonal medicine (such as oral contraceptives, ovulation-inducing agents, and anti-androgens) in the previous 3 months of the research, were excluded.

The selection of the control subjects was based on the enrollment of the healthy women population having no history of PCOS with the regular menstrual cycle (menstrual period up to 7 days and menstrual cycle of 21-35 days), normal androgen levels and no symptoms of hirsutism. The control women were matched with PCOS women for age and BMI.

To collect demographic and clinical data of the patients, we prepared a specially designed questionnaire, and the demographic characteristics (age, weight, height, waist, and hip measurements), history of the menstrual cycle, hirsutism, acne, and previous disease and drug history were recorded. For patients with doubtful records, biochemical laboratory tests and ultrasound investigations were performed. The confirmed cases of PCOS were recruited. Controls were screened for biochemical signs of raised androgens, ultrasonic ovarian morphology, and menstrual health records. Only those with normal results were included in the study.

For each enrolled woman, BMI (weight in $\mathrm{kg}$ divided by height in $\mathrm{m}^{2}$ ) was calculated. Likewise, the calculation of waist-hip ratio was based on measurements of waist circumference by an experienced nurse (the narrowest circumference between the lower costal margins and the iliac crest) and hip circumference (the maximum circumference at the level of the femoral trochanters) with the proper standing position of the study subjects.

\section{Sample collection}

In both groups of the study subjects, the blood samples were collected between days 3 and 6 of the menstrual cycle, at about 8:00 am. Each subject was requested to attend the clinic in a fasting state, and $10 \mathrm{ml}$ of the blood sample was drawn from each subject using the venipuncture method. A total of $5 \mathrm{ml}$ of this blood was transferred in an EDTA coated vial, and immediately processed for obtaining buffy coat and plasma, through centrifugation process. Buffy coat was used for DNA extraction, and the plasma was used for the estimation of kisspeptin. Remaining $5 \mathrm{ml}$ of the blood sample was drawn in a red top tube and used to obtain serum by centrifugation process, for the evaluation of FSH and $\mathrm{LH}$. All samples were consequently stored at $-80 \mathrm{oC}$ until experimental analysis.

\section{Estimation of kisspeptin, FSH and LH levels}

The blood plasma level of kisspeptin was measured using an enzyme-linked immunosorbent assay (ELISA) kit from Phoenix Pharmaceuticals Inc., Belmond, CA, following extraction with Phoenix Peptide sep-columns
(RK-Sepcol-2). Blood serum levels of FSH and LH were also measured by a specific ELISA kit (Human, Cat. No.65205.GER).

\section{KISS1 genotyping analysis}

KISS1 gene is mapped on chromosome 1q32 with its four exons (Fig. 1). Genomic DNA from 104 PCOS patients and 109 controls were obtained, and PCR sequencing was performed for obtaining SNPs of the KISS1 gene. For this purpose, the buffy coat was used to extract the genomic DNA, utilizing a DNA extraction kit from Puregene (Puregene Blood Kit, QIAGEN, Cat. No. 158389, USA). Polymerase chain reaction (PCR) was performed using the following forward and reverse primers: F: 5 '-ACCTGC CGAACTACA ACTGG-3, R: 5'-TGAAGGAACAGGCG GTTAGT-3', under the following conditions: initial denaturation step at $95^{\circ} \mathrm{C}$ for $15 \mathrm{~min}$, followed by 34 cycles of denaturation at $95^{\circ} \mathrm{C}$ for $1 \mathrm{~min}$, annealing at $60^{\circ} \mathrm{C}$ for $1 \mathrm{~min}$, and extension at $72^{\circ} \mathrm{C}$ for $1 \mathrm{~min}$, with the final extension of $10 \mathrm{~min}$ at $72{ }^{\circ} \mathrm{C}$. The size of the PCR product was $353 \mathrm{bp}$. The nucleotide sequencing of the PCR product was carried out using the ABI Big Dye Terminator protocol on ABI 3100 Avant Genetic Analyzer.

\section{Statistical analysis}

The statistical analyses were conducted using SPSS for Windows (version 20.0). The descriptive characteristics of the different continuous variables were expressed as mean \pm SD. The Student's t-test was used to obtain the significance of the difference in the mean values of continuous variables between PCOS patients and controls. Genotype and allele frequencies of the KISS1 gene polymorphisms were calculated for both study groups, and the significance of the difference was determined using the Chi-Square test. Odds ratio (OR), its 95\% confidence interval $(\mathrm{CI})$, and $p$-values were obtained. Hardy Weinberg equilibrium was tested.

The levels of PCOS associated variables were analyzed in the different genotypes of each identified SNP of the KISS1 gene. The Pairwise t-test was used to assess the significance of the difference between wild-type homozygous and mutant allele carriers (mutant homozygous and heterozygous). A $p$-value $<0.05$ was considered as statistically significant.

\section{Results}

\section{Demographic and endocrine characteristics of study subjects}

The demographic characteristics of PCOS patients and controls are presented in Table 1. A significant difference was noted between PCOS patients and controls, only in the value of the waist-hip ratio $(p<0.001)$ while the age $(p=0.88)$ and BMI $(p=0.63)$ exhibited no significant difference between the study groups. 


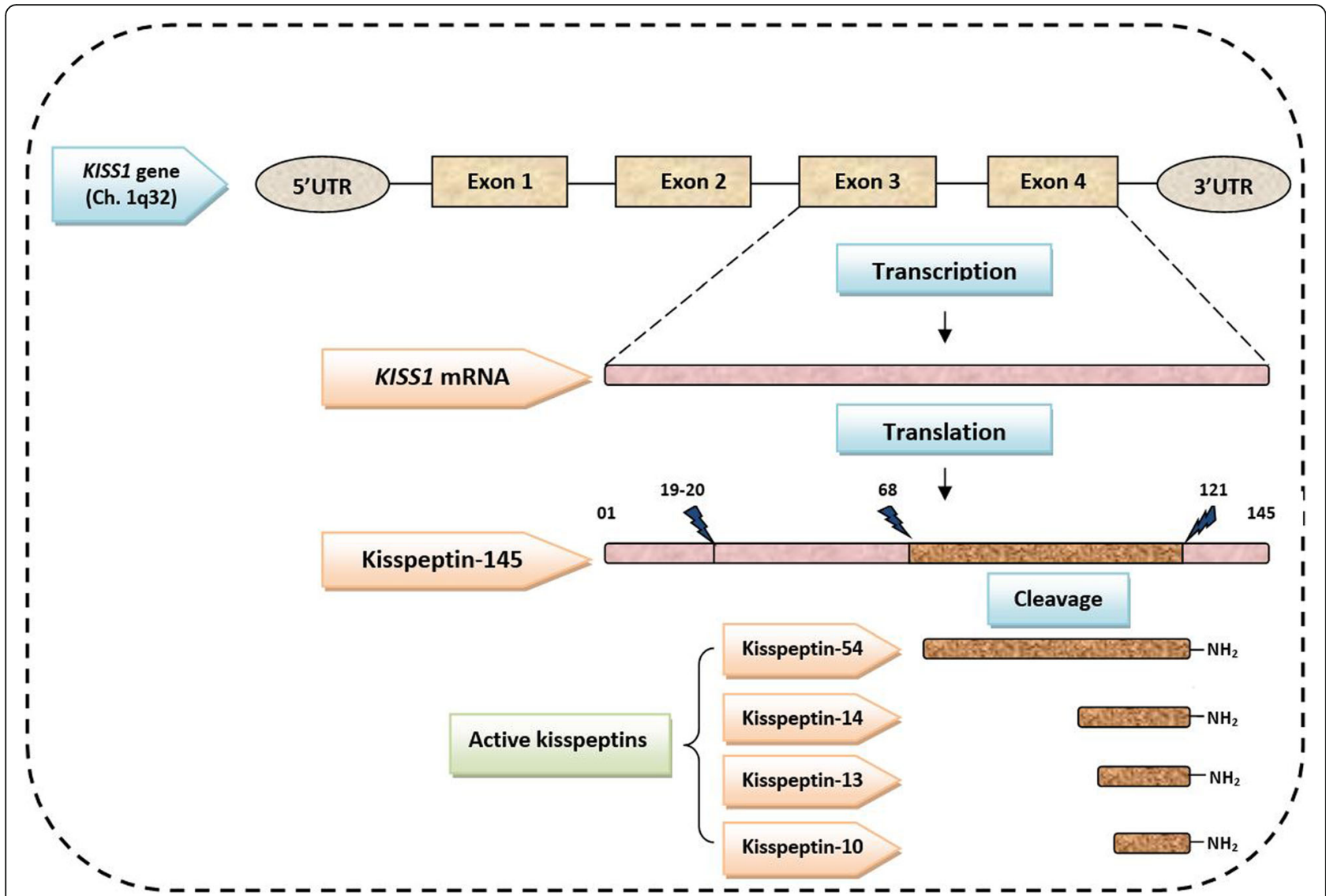

Fig. 1 Representation of the Human KISS1 gene with its exons and protein product (kisspeptin). THE Human KISS1 gene is mapped on chromosome 1q32. It consists of four exons, of which only third and fourth exons are finally translated into the 145 amino acid peptide, and it is cleaved into four forms of active kisspeptin containing 54, 14, 13, and 10 amino acids

As shown in Table 1, the levels of kisspeptin $(p=$ $0.415)$ and FSH showed ( $p=0.223)$ no significant difference between PCOS patients and controls. A significant elevation in the level of LH for the PCOS patients ( $p=$ 0.0001 ) was the most noticeable result, as the level was more than three-fold higher in PCOS patients than in the controls. Furthermore, when both groups were examined for the values of the LH-FSH ratio, a significant difference $(p=0.0001)$ was noted.

\section{KISS1 gene polymorphisms}

A total of six SNPs were identified through sequencing of the KISS1 gene. The results of three SNPs (rs372790354 G/A, rs12998 G/A, and rs35431622 A/T)

Table 1 Demographic and endocrine characteristics of study subjects

\begin{tabular}{llll}
\hline Characteristics & PCOS Patients $(\boldsymbol{n}=104)$ (Mean \pm SD) & Controls $(\boldsymbol{n}=109)($ Mean \pm SD) & $\boldsymbol{p}$-value \\
\hline Age $($ Years $)$ & $25.06 \pm 3.88$ & $24.96 \pm 5.56$ & 0.886 \\
Waist $(\mathbf{c m})$ & $87.86 \pm 13.82$ & $86.15 \pm 17.09$ & 0.422 \\
Hip $(\mathbf{c m})$ & $104.39 \pm 11.39$ & $110.48 \pm 14.78$ & $0.001^{*}$ \\
Waist-Hip ratio & $0.84 \pm 0.07$ & $0.77 \pm 0.06$ & $0.0001^{*}$ \\
BMI $\left(\mathbf{K g} / \mathbf{m}^{2}\right)$ & $29.45 \pm 5.99$ & $29.89 \pm 7.31$ & 0.633 \\
Kisspeptin $(\mathbf{n g} / \mathbf{m l})$ & $0.41 \pm 0.16$ & $0.39 \pm 0.07$ & 0.415 \\
FSH $(\mathbf{I U} / \mathbf{L})$ & $5.09 \pm 1.54$ & $4.83 \pm 1.55$ & 0.223 \\
LH $(\mathbf{I U} / \mathbf{L})$ & $14.43 \pm 7.48$ & $4.56 \pm 1.38$ & $0.0001^{*}$ \\
LH-FSH ratio & $2.94 \pm 1.07$ & $0.98 \pm 0.37$ & $0.0001^{*}$ \\
\hline
\end{tabular}

*Significant, $p$ values refer to Student's t-test; $L H$ luteinizing hormone, FSH follicle stimulating hormone, BMI body mass index 
Table 2 Single nucleotide polymorphisms identified in the KISS1 gene by sequencing

\begin{tabular}{|c|c|c|c|c|c|c|c|c|}
\hline $\mathrm{db}$ SNP ID & Chromosome Position & mRNA position & Heterozygosity & MAF & Allele & Location & Function & Amino-acid change \\
\hline rs372790354 & Chr1:204196427 & - & - & - & $G>A$ & 5 Prime UTR variant & NA & - \\
\hline rs12998 & Chr1:204192819 & 212 & 0.093 & 0.023 & $G>A$ & Exon 1 & Non-synonymous & p.Glu20Lys \\
\hline rs35431622 & Chr1:204190794 & 261 & 0.103 & 0.075 & $A>T$ & Exon 2 & Non-synonymous & p.Gln36Leu \\
\hline
\end{tabular}

db SNP ID single nucleotide polymorphism Database ID, MAF minor allele frequency

(Table 2), are presented in this paper. The SNP rs372790354 G/A was novel and was located in the 5' untranslated region (5'UTR). The other two SNPs, rs12998 G/A, and rs35431622 A/T were also characterized as novel SNPs, and these were positioned in the exon 1 and exon 2, respectively. The rs12998 G/A is a non-synonymous SNP and results in the substitution of Glutamic acid at position 20 by a basic amino acid Lysine. The third identified SNP rs35431622 A/T was also a non-synonymous which results in the substitution of Glutamine with Leucine at position 36.

\section{Genotype and allele frequencies of the KISS1 gene polymorphisms}

The genotype and allele frequencies of the identified SNPs of the KISS1 gene are presented in Tables 3 and 4. The frequencies of the genotypes (GA and AA) of rs372790354 were significantly different $(p<0.05)$ between PCOS patients and controls. The GA genotype occurred at a lower frequency among PCOS patients as compared to controls, while the genotype AA was observed only in the PCOS patients. The $G$ allele of rs372790354 was protective, and the frequency of allele A was significantly $(p=0.021)$ higher in PCOS patients compared to controls (Table 4). The Hardy-Weinberg equilibrium was maintained for PCOS and control subjects with $p$-values of $>0.05$ and 1.00 , respectively.
For the SNP rs12998, the genotype frequencies were not significantly $(p>0.05)$ different between PCOS patients and controls. The GA genotype was more frequently observed in controls compared to PCOS patients, but the difference was not statistically significant. This SNP exhibited the Hardy-Weinberg equilibrium $(p>0.05)$ for both study groups.

Likewise, the genotypes TA and AA of the polymorphism rs35431622 showed no significant influence on the risk of PCOS. The homozygous genotype TT was not identified in the PCOS patients and controls. The Hardy-Weinberg equilibrium was maintained $(p>0.05)$ for this SNP in both the PCOS and control subjects. As illustrated in Table 4. the allele frequencies of these two SNPs (rs12998 G/A and rs35431622 A/T) were not significantly different between PCOS patients and controls.

\section{Influence of KISS1 gene polymorphisms on PCOS associated endocrine and obesity linked variables}

To study the probable impact of the three studied SNPs (rs372790354 G/A, rs12998 G/A, and rs35431622 A/T) of the KISS1 gene, on the levels of PCOS associated variables, the PCOS patients and controls were grouped based on their genotypes. The values of endocrine ( $\mathrm{LH}$, FSH, LH-FSH ratio, and kisspeptin) and obesity-linked parameters (BMI and waist-hip ratio), were determined in the different genotypes. The comparison analysis was

Table 3 Genotype frequencies of studied SNPs of the KISS1 gene, in PCOS patients and controls

\begin{tabular}{|c|c|c|c|c|c|c|c|}
\hline \multirow[t]{2}{*}{ SNPS } & \multirow[t]{2}{*}{ Genotypes } & \multicolumn{3}{|l|}{ Frequency } & \multirow[t]{2}{*}{ OR $(95 \% \mathrm{Cl})$} & \multirow[t]{2}{*}{$x^{2}$} & \multirow{2}{*}{$\begin{array}{l}\boldsymbol{p}^{-} \\
\text {value }\end{array}$} \\
\hline & & PCOS patients n (\%) & Controls n (\%) & Total n (\%) & & & \\
\hline \multirow[t]{4}{*}{ rs372790354 G/A } & GG & $86(82.7 \%)$ & $92(84.4 \%)$ & $178(83.6 \%)$ & Reference & & \\
\hline & GA & $13(12.5 \%)$ & 17 (15.6\%) & $30(14.1 \%)$ & $0.07(0.01-1.38)$ & 5.51 & $0.018^{*}$ \\
\hline & AA & $5(4.8 \%)$ & $0(0.0 \%)$ & $5(2.3 \%)$ & $1.17(0.64-215)$ & 5.20 & $0.022^{*}$ \\
\hline & Total & 104 (100.0\%) & 109 (100.0\%) & $213(100.0 \%)$ & & & \\
\hline \multirow[t]{4}{*}{ rs12998 G/A } & GG & $87(83.7 \%)$ & $88(80.7 \%)$ & $175(82.2 \%)$ & Reference & & \\
\hline & GA & $12(11.5 \%)$ & $17(15.6 \%)$ & 29 (13.6\%) & $0.56(0.13-2.55)$ & 0.56 & 0.454 \\
\hline & AA & $5(4.8 \%)$ & $4(3.7 \%)$ & $9(4.2 \%)$ & $1.26(0.33-4.86)$ & 0.12 & 0.732 \\
\hline & Total & 104 (100.0\%) & 109 (100.0\%) & $213(100.0 \%)$ & & & \\
\hline \multirow[t]{4}{*}{ rs35431622 A/T } & $\mathrm{AA}$ & 97 (93.3\%) & 101 (92.7\%) & $198(92.96 \%)$ & Reference & & \\
\hline & AT & $7(6.7 \%)$ & $8(7.3 \%)$ & $15(7.04 \%)$ & $0.91(0.32-2.61)$ & 0.03 & 0.862 \\
\hline & $\pi$ & $0(0.0 \%)$ & $0(0.0 \%)$ & $0(0.0 \%)$ & - & - & - \\
\hline & Total & 104 (100.0\%) & 109 (100.0\%) & $213(100.0 \%)$ & & & \\
\hline
\end{tabular}

*Significant, $p$ values refer to $C h i-S q u a r e ~\left(\mathbf{x}^{2}\right)$ test, $O R$ odds ratio, $\mathrm{Cl}$ confidence interval 
Table 4 Allele frequencies of studied SNPs of the KISS1 gene, in PCOS patients and controls

\begin{tabular}{|c|c|c|c|c|c|c|c|}
\hline \multirow[t]{2}{*}{ SNPS } & \multirow[t]{2}{*}{ Alleles } & \multicolumn{3}{|l|}{ Frequency } & \multirow[t]{2}{*}{ OR $(95 \% \mathrm{Cl})$} & \multirow[t]{2}{*}{$x^{2}$} & \multirow{2}{*}{$\begin{array}{l}\boldsymbol{p} \text { - } \\
\text { value }\end{array}$} \\
\hline & & PCOS patients (\%) & Controls (\%) & Total (\%) & & & \\
\hline \multirow[t]{3}{*}{ rs372790354 G/A } & $G$ & $88.9 \%$ & $92.2 \%$ & $90.6 \%$ & $0.680(0.35-1.31)$ & 1.33 & $0.021^{*}$ \\
\hline & A & $11.1 \%$ & $7.8 \%$ & $9.4 \%$ & & & \\
\hline & Total & $100.0 \%$ & $100.0 \%$ & $100.0 \%$ & & & \\
\hline \multirow[t]{3}{*}{ rs12998 G/A } & G & $89.4 \%$ & $88.5 \%$ & $88.97 \%$ & $1.09(0.59-2.01)$ & 0.09 & 0.769 \\
\hline & A & $10.6 \%$ & $11.5 \%$ & $11.03 \%$ & & & \\
\hline & Total & $100.0 \%$ & $100.0 \%$ & $100.0 \%$ & & & \\
\hline \multirow[t]{3}{*}{ rs35431622 A/T } & A & $96.6 \%$ & $96.3 \%)$ & $96.5 \%$ & $1.09(0.38-3.07)$ & 0.03 & 0.864 \\
\hline & $\mathrm{T}$ & $3.4 \%$ & $3.7 \%$ & $3.5 \%$ & & & \\
\hline & Total & $100.0 \%$ & $100.0 \%$ & $100.0 \%$ & & & \\
\hline
\end{tabular}

*Significant, $p$ values refer to $C$ i-Square $\left(\mathbf{x}^{\mathbf{2}}\right)$ test, $O R$ odds ratio, $C l$ confidence interval

performed between wild type homozygous and mutant allele carriers (mutant homozygous and heterozygous). The results are presented in Tables 5 and 6 . The SNP rs372790354 was revealed to exhibit a significant influence $(P<0.05)$ on the endocrine ( $\mathrm{LH}$ and kisspeptin) and obesity-linked (waist-hip ratio) parameters of PCOS patients. While other parameters (FSH, LH-FSH ratio, and $\mathrm{BMI}$ ) of PCOS patients were not influenced by rs372790354. When the influence of this SNP on the studied parameters of control subjects was investigated, no significant difference was obtained (Table 5).

The other two SNPs: rs12998 G/A, and rs35431622 A/ $\mathrm{T}$, exhibited no significant influence on the values of endocrine as well as obesity liked parameters in the PCOS patients. Likewise, in the control group, no significant differences were observed for the levels of the studied parameters between the genotypes of these two SNPs (Table 6).

Haplotype analysis was carried out using SNPstat, and the results are presented in Table 7. Five haplotypes exhibited polymorphism in the PCOS and control group. The most frequently identified haplotype in both groups was GGA (rs12998, rs372790354, and rs35431622), but the results in the two groups were not significantly different. None of the other haplotypes showed any significant difference between the patients and controls.

\section{Discussion}

The present study describes the probable influence of three identified SNPs (rs372790354 G/A, rs12998 G/A, and rs35431622 A/T) in the KISS1 gene in PCOS pathogenesis. Importantly, for the first time, we have attempted to demonstrate the influence of these three novel SNPs on the endocrine (kisspeptin, LH, FSH, LHFSH ratio) and obesity-linked parameters (BMI and waist-hip ratio), in women with and without PCOS.

The genotype and allele frequencies were calculated and compared between PCOS patients and controls to elucidate the role of these studied SNPs in PCOS. For the SNP rs372790354, the genotypes AA and GA exhibited significant association with the risk of PCOS. The mutant AA genotype was found only in PCOS patients, and the frequency of the GA genotype was significantly higher in control subjects. The allele $G$ showed a protective effect.

In recent years, the KISS1 gene has been addressed as one of the crucial regulators in controlling the function and maturation of the reproductive system [20]. This gene consists of four exons, of which only third and fourth exons are finally translated into 145 amino acids and is cleaved into shorter four forms of kisspeptin containing amino acids of 54,14,13, and 11 and exhibit the same affinity for their receptor-GPR54 [8]. The role of kisspeptin (a major product of KISS1 gene) has been well identified in puberty, ovulation, brain sex differentiation, and fertility, with an essential regulatory function in the normal release of hypothalamic GnRH and consequently in $\mathrm{LH}$ secretion $[21,22]$. The pathophysiological mechanism of PCOS is also reflected in the inappropriate $\mathrm{GnRH} / \mathrm{LH}$ secretion [23, 24]. However, clear evidence for the role of $K I S S 1 /$ kisspeptin expression in the mechanism of PCOS pathogenesis is still not obtained.

In this study, the results showed that the SNP rs372790354, which is significantly different in PCOS patients, is located in the 5'UTR (untranslated region) of the KISS1 gene. The 5'UTR has been recognized as playing an important role in the regulation of gene expression through regulating the process of RNA transcription, mRNA stability and its localization, and translational efficiency $[25,26]$. Moreover, 5'UTR efforts great contribution in the initiation step of translation. The multi-step process of gene expression is primarily depended on this initiation translation step [27].

Keeping in view the role of 5 'UTR in gene expression regulation, our study has hypothesized that the rs372790354 polymorphism of the KISS1 gene, can 
Table 5 Influence of rs372790354 polymorphism of KISS1 gene on Endocrine and Obesity linked parameters, in PCOS patients and controls

\begin{tabular}{|c|c|c|c|c|c|}
\hline \multirow[t]{4}{*}{ Parameters } & \multirow[b]{3}{*}{ No. C } & \multicolumn{3}{|c|}{ Genotypes of rs372790354 } & \multirow{4}{*}{$\begin{array}{l}\boldsymbol{P} \text {-value (Pair } \\
\text { wise } \\
\text { Comparison) }\end{array}$} \\
\hline & & \multirow{2}{*}{$\boldsymbol{n}=92$} & \multirow{2}{*}{$\begin{array}{l}\text { GA } \\
\boldsymbol{n}=17\end{array}$} & \multirow{2}{*}{$\begin{array}{l}\mathrm{AA} \\
\boldsymbol{n}=0\end{array}$} & \\
\hline & & & & & \\
\hline & No. P & $\boldsymbol{n}=86$ & $\boldsymbol{n}=13$ & $\boldsymbol{n}=5$ & \\
\hline \multicolumn{6}{|c|}{ Obesity linked Parameters } \\
\hline \multirow[t]{4}{*}{ BMI $\left(K g \backslash m^{2}\right)$} & C & $29.88 \pm 7.21$ & $29.89 \pm 8.06$ & - & $\mathrm{GG} / \mathrm{GA}=0.776$ \\
\hline & & & & & - \\
\hline & $P$ & $29.43 \pm 5.90$ & $29.62 \pm 5.01$ & $29.40 \pm 10.4$ & $\mathrm{GG} / \mathrm{GA}=0.902$ \\
\hline & & & & & $\mathrm{GG} / \mathrm{AA}=0.991$ \\
\hline \multirow[t]{4}{*}{ Waist-hip ratio } & C & $0.77 \pm 0.06$ & $0.79 \pm 0.07$ & - & $\mathrm{GG} / \mathrm{GA}=0.389$ \\
\hline & & & & & - \\
\hline & $P$ & $0.83 \pm 0.07$ & $0.84 \pm 0.08$ & $0.88 \pm 0.16$ & $\mathrm{GG} / \mathrm{GA}=0.925$ \\
\hline & & & & & $\mathrm{GG} / \mathrm{AA}<0.05^{*}$ \\
\hline \multicolumn{6}{|c|}{ Endocrine Parameters } \\
\hline \multirow[t]{4}{*}{ FSH (IU\L) } & C & $4.76 \pm 1.60$ & $5.17 \pm 1.22$ & - & $\mathrm{GG} / \mathrm{GA}=0.063$ \\
\hline & & & & & - \\
\hline & $P$ & $5.16 \pm 1.53$ & $4.41 \pm 1.08$ & $5.52 \pm 2.39$ & $\mathrm{GG} / \mathrm{GA}=0.092$ \\
\hline & & & & & $\mathrm{GG} / \mathrm{AA}=0.624$ \\
\hline \multirow[t]{4}{*}{$\mathrm{LH}(I \cup \backslash \mathrm{L})$} & C & $4.53 \pm 1.45$ & $4.68 \pm 1.02$ & - & $\mathrm{GG} / \mathrm{GA}=0.135$ \\
\hline & & & & & - \\
\hline & $P$ & $12.54 \pm 2.55$ & $11.85 \pm 3.43$ & $14.93 \pm 8.02$ & $\mathrm{GG} / \mathrm{GA}=0.051$ \\
\hline & & & & & $\mathrm{GG} / \mathrm{AA}<0.05^{*}$ \\
\hline \multirow[t]{4}{*}{ LH-FSH ratio } & C & $0.99 \pm 0.39$ & $0.94 \pm 0.26$ & - & $\mathrm{GG} / \mathrm{GA}=0.277$ \\
\hline & & & & & - \\
\hline & $P$ & $2.96 \pm 1.08$ & $2.91 \pm 1.12$ & $2.45 \pm 0.62$ & $\mathrm{GG} / \mathrm{GA}=0.881$ \\
\hline & & & & & $\mathrm{GG} / \mathrm{AA}=0.144$ \\
\hline \multirow[t]{4}{*}{ Kisspeptin (ng \ml) } & C & $0.42 \pm 0.15$ & $0.37 \pm 0.06$ & - & $\mathrm{GG} / \mathrm{GA}=0.106$ \\
\hline & & & & & - \\
\hline & $P$ & $0.41 \pm 0.16$ & $0.42 \pm 0.15$ & $0.28 \pm 0.19$ & $\mathrm{GG} / \mathrm{GA}=0.887$ \\
\hline & & & & & $\mathrm{GG} / \mathrm{AA}<0.05^{*}$ \\
\hline
\end{tabular}

*Significant, C control, P PCOS patients, BMI Body mass index, LH luteinizing hormone, FSH follicle stimulating hormone, $p$ values indicate comparison of features between wild-type homozygous and mutant allele carriers (mutant homozygous and heterozygous)

dysregulate the multi-step process of gene expression. This step may indirectly promote alteration in the functional activity of the KISS1 gene product- kisspeptin and its receptor GPR54. The clear evidence for the considerable influence of the SNP rs372790354 on kisspeptin level of PCOS women is illustrated in Table 4, which highlights a significant difference in kisspeptin level, between homozygous wild-type (GG) and mutant (AA) genotypes of this SNP. While in the control group, the level of kisspeptin was not influenced by any of the genotypes of rs372790354.

Moreover, when both study groups were compared for the level of kisspeptin (Table 1), no significant difference was obtained between PCOS patients and controls. No significant elevation of the kisspeptin level in PCOS patients in our study may be due to the small sample size. One of our previous studies, reported by Albalawi et al. [9], also highlights no significant difference in the level of kisspeptin between PCOS women and controls. It showed that the SNP rs4889 exhibited a significant influence on the kisspeptin level. Several previous studies have also shown a non-significant difference in the level of kisspeptin in women with PCOS as compared to nonPCOS women $[28,29]$. Thus, these observations of our study suggest that the kisspeptin level of PCOS women was not significantly higher as compared to controls, but is significantly influenced by the SNP rs372790354 of KISS1 gene.

It is well established that PCOS has a complex multifactorial etiology and is associated with increased 
Table 6 Influence of rs12998 and rs35431622 polymorphisms of KISS1 gene on Endocrine and Obesity linked parameters, in PCOS patients and controls

\begin{tabular}{|c|c|c|c|c|c|c|c|c|}
\hline \multirow[t]{4}{*}{ Parameters } & \multirow[b]{3}{*}{ No. C } & \multicolumn{3}{|c|}{ Genotypes of rs12998 } & \multirow{4}{*}{$\begin{array}{l}\boldsymbol{P} \text {-value (Pair } \\
\text { wise } \\
\text { Comparison) }\end{array}$} & \multicolumn{2}{|c|}{ Genotypes of rs35431622 } & \multirow{4}{*}{$\begin{array}{l}\boldsymbol{P} \text {-value (Pair } \\
\text { wise } \\
\text { Comparison) }\end{array}$} \\
\hline & & \multirow{2}{*}{$\begin{array}{l}\mathrm{GG} \\
\boldsymbol{n}=88\end{array}$} & \multirow{2}{*}{$\begin{array}{l}\mathrm{GA} \\
\boldsymbol{n}=17\end{array}$} & \multirow{2}{*}{$\begin{array}{l}\mathrm{AA} \\
\boldsymbol{n}=4\end{array}$} & & \multirow{2}{*}{$\begin{array}{l}\mathrm{AA} \\
\boldsymbol{n}=101\end{array}$} & \multirow{3}{*}{$\begin{array}{l}\text { AT } \\
\boldsymbol{n}=8 \\
\boldsymbol{n}=7\end{array}$} & \\
\hline & & & & & & & & \\
\hline & No. P & & $\boldsymbol{n}=12$ & $\boldsymbol{n}=5$ & & $\boldsymbol{n}=97$ & & \\
\hline \multicolumn{9}{|c|}{ Obesity linked Parameters } \\
\hline \multirow[t]{4}{*}{ BMI $\left(K g \backslash m^{2}\right)$} & C & $29.82 \pm 7.04$ & $30.45 \pm 9.33$ & $29.00 \pm 4.02$ & $\mathrm{GG} / \mathrm{GA}=0.752$ & $29.54 \pm 7.18$ & $34.27 \pm 7.95$ & $\mathrm{AA} / \mathrm{AT}=0.987$ \\
\hline & & & & & $\mathrm{GG} / \mathrm{AA}=0.503$ & & & \\
\hline & $P$ & $29.44 \pm 5.86$ & $28.88 \pm 5.48$ & $31.04 \pm 9.96$ & $\mathrm{GG} / \mathrm{GA}=0.748$ & $29.55 \pm 6.05$ & $28.11 \pm 5.32$ & $\mathrm{AA} / \mathrm{AT}=0.987$ \\
\hline & & & & & $\mathrm{GG} / \mathrm{AA}=0.740$ & & & \\
\hline \multirow[t]{4}{*}{ Waist-hip ratio } & C & $0.77 \pm 0.07$ & $0.79 \pm 0.07$ & $0.79 \pm 0.06$ & $\mathrm{GG} / \mathrm{GA}=0.218$ & $0.77 \pm 0.06$ & $0.79 \pm 0.09$ & $\mathrm{AA} / \mathrm{AT}=0.640$ \\
\hline & & & & & $\mathrm{GG} / \mathrm{AA}=0.420$ & & & \\
\hline & $P$ & $0.84 \pm 0.07$ & $0.81 \pm 0.07$ & $0.89 \pm 0.15$ & $\mathrm{GG} / \mathrm{GA}=0.254$ & $0.84 \pm 0.07$ & $0.81 \pm 0.06$ & $\mathrm{AA} / \mathrm{AT}=0.965$ \\
\hline & & & & & $\mathrm{GG} / \mathrm{AA}=0.317$ & & & \\
\hline \multicolumn{9}{|c|}{ Endocrine Parameters } \\
\hline \multirow[t]{4}{*}{ FSH (IU\L) } & C & $4.73 \pm 1.54$ & $5.04 \pm 1.48$ & $6.10 \pm 1.83$ & $\mathrm{GG} / \mathrm{GA}=0.434$ & $4.84 \pm 1.50$ & $4.61 \pm 2.16$ & $\mathrm{AA} / \mathrm{AT}=0.070$ \\
\hline & & & & & $\mathrm{GG} / \mathrm{AA}=0.230$ & & & \\
\hline & $P$ & $5.11 \pm 1.53$ & $4.59 \pm 1.26$ & $5.80 \pm 2.18$ & $\mathrm{GG} / \mathrm{GA}=0.212$ & $5.07 \pm 1.53$ & $5.20 \pm 1.77$ & $\mathrm{AA} / \mathrm{AT}=0.972$ \\
\hline & & & & & $\mathrm{GG} / \mathrm{AA}=0.343$ & & & \\
\hline \multirow[t]{4}{*}{$\mathrm{LH}(I \cup \backslash \mathrm{L})$} & C & $4.55 \pm 1.42$ & $4.43 \pm 1.25$ & $5.20 \pm 1.53$ & $\mathrm{GG} / \mathrm{GA}=0.738$ & $4.54 \pm 1.35$ & $4.81 \pm 1.86$ & $\mathrm{AA} / \mathrm{AT}=0.163$ \\
\hline & & & & & $\mathrm{GG} / \mathrm{AA}=0.460$ & & & \\
\hline & $P$ & $14.88 \pm 8.03$ & $11.36 \pm 2.47$ & $13.82 \pm 2.67$ & $\mathrm{GG} / \mathrm{GA}=0.135$ & $14.46 \pm 7.69$ & $13.95 \pm 3.72$ & $\mathrm{AA} / \mathrm{AT}=0.466$ \\
\hline & & & & & $\mathrm{GG} / \mathrm{AA}=0.488$ & & & \\
\hline \multirow[t]{4}{*}{ LH-FSH ratio } & C & $0.99 \pm 0.38$ & $0.94 \pm 0.38$ & $0.87 \pm 0.25$ & $\mathrm{GG} / \mathrm{GA}=0.526$ & $0.97 \pm 0.37$ & $1.11 \pm 0.34$ & $\mathrm{AA} / \mathrm{AT}=0.798$ \\
\hline & & & & & $\mathrm{GG} / \mathrm{AA}=0.534$ & & & \\
\hline & $P$ & $2.97 \pm 1.06$ & $2.82 \pm 1.29$ & $2.55 \pm 0.71$ & $\mathrm{GG} / \mathrm{GA}=0.650$ & $2.94 \pm 1.09$ & $2.85 \pm 0.88$ & $\mathrm{AA} / \mathrm{AT}=0.695$ \\
\hline & & & & & $\mathrm{GG} / \mathrm{AA}=0.263$ & & & \\
\hline \multirow[t]{4}{*}{ Kisspeptin (ng\ml) } & C & $0.39 \pm 0.07$ & $0.37 \pm 0.05$ & $0.40 \pm 0.10$ & $\mathrm{GG} / \mathrm{GA}=0.150$ & $0.39 \pm 0.06$ & $0.41 \pm 0.07$ & $\mathrm{AA} / \mathrm{AT}=0.811$ \\
\hline & & & & & $\mathrm{GG} / \mathrm{AA}=0.946$ & & & \\
\hline & $P$ & $0.42 \pm 0.16$ & $0.38 \pm 0.14$ & $0.31 \pm 0.25$ & $\mathrm{GG} / \mathrm{GA}=0.399$ & $0.41 \pm 0.16$ & $0.35 \pm 0.11$ & $\mathrm{AA} / \mathrm{AT}=0.184$ \\
\hline & & & & & $\mathrm{GG} / \mathrm{AA}=0.156$ & & & \\
\hline
\end{tabular}

*Significant, $C$ control, $P$ PCOS patients, BMI Body mass index, LH luteinizing hormone, FSH follicle stimulating hormone, $p$ values indicate comparison of features between wild-type homozygous and mutant allele carriers (mutant homozygous and heterozygous). For SNP rs35431622: $\Pi=0$, in both PCOS patients and controls

Table 7 Construction of haplotypes of the three studied SNP in the PCOS patients and control group

\begin{tabular}{|c|c|c|c|c|c|c|c|}
\hline \multirow{3}{*}{$\begin{array}{l}\text { Serial } \\
\text { No. }\end{array}$} & \multicolumn{3}{|c|}{ Haplotype } & \multirow{3}{*}{$\begin{array}{l}\text { Freq. } \\
\text { Control }\end{array}$} & \multirow{3}{*}{$\begin{array}{l}\text { Freq. } \\
\text { Case }\end{array}$} & \multirow[t]{3}{*}{ OR (95\% Cl) } & \multirow{3}{*}{$\begin{array}{l}P \text { - } \\
\text { value }\end{array}$} \\
\hline & \multicolumn{3}{|l|}{$\overline{S N P}$} & & & & \\
\hline & rs12998 & rs372790354 & rs35431622 & & & & \\
\hline 1 & G & G & A & 0.8413 & 0.8302 & 1.00 & - \\
\hline 2 & $A$ & $A$ & A & 0.0508 & 0.0665 & $1.22(0.56-2.63)$ & 0.62 \\
\hline 3 & A & G & A & 0.0516 & 0.0393 & $0.82(0.37-1.78)$ & 0.61 \\
\hline 4 & G & $A$ & A & 0.0196 & 0.0304 & $1.43(0.47-4.33)$ & 0.53 \\
\hline 5 & G & G & G & 0.0244 & 0.02 & $0.74(0.18-3.05)$ & 0.68 \\
\hline
\end{tabular}


secretion of $\mathrm{LH}$, normal or low level of FSH, and an increased ratio of LH-FSH $[30,31]$. In our study, PCOS patients showed significantly higher values of $\mathrm{LH}$ and LH-FSH ratio as compared to controls. While the level of FSH was almost the same between the two study groups. Likewise, many previous reports highlighted a significantly elevated level of LH and increased LH-FSH ratio in PCOS subjects with no significant alteration in the FSH level, compared to controls [32, 33]. Importantly, when the influence of the SNP rs372790354 on endocrine parameters (LH, FSH, and LH-FSH ratio) was investigated, it was seen that the level of $\mathrm{LH}$ in the PCOS group was influenced by this SNP and was significantly higher in mutant AA genotype. While, in the control group, no significant influence of SNP rs372790354 was observed. Likewise, the level of FSH and LH-FSH ratio showed no significant difference in the genotypes of this SNP in both study groups. These results suggest a significant influence of the AA genotype of rs372790354 on increased LH levels of PCOS women.

Results of several previous studies show that the pathology of PCOS is influenced by the obesity-linked parameters, including BMI and WHR [34, 35]. Hence, we also determined the values of BMI and WHR in both PCOS and control subjects and then observed any possible effects of rs372790354 on these obesity-linked parameters. Our results showed that there was no difference in BMI in the two groups, but WHR was significantly different. These findings confirm the results of other recent studies $[17,36]$. Further, when the influence of rs372790354 was investigated on BMI and WHR, only WHR in PCOS patients showed a significant difference between the genotypes (GG and AA).

Based on these findings, we suggest that the rs372790354 polymorphism of the KISS1 gene may have a direct effect on the functional activity of kisspeptin in terms of its altered behavior towards receptor GPR54. Consequently, the disturbed kisspeptin-GPR54 pathway encourages dysregulation in GnRH secretion, which further leads to the hypersecretion of LH. Subsequently, the condition of hyperandrogenism with a high level of testosterone is induced by the direct action of high stimulation of LH on gonads. Eventually, all these conditions may favor the increase in the risk of PCOS.

Many recent reports have suggested the role of altered behavior of kisspeptin as a major cause in inducing hyperandrogenism associated with PCOS $[3,37]$. In this present study, we have suggested the role of SNP rs372790354 of the KISS1 gene in creating a disturbance in the functional activity of kisspeptin with hypersecretion of LH, which in turn may be responsible for increasing the risk of PCOS. No other previous studies are available in the literature to compare the results of our study. However, the association of this polymorphism with PCOS should be confirmed by further studies, as the sample size in this study is relatively small and does not give strong evidence for these related findings.

The other identified SNPs rs12998 G/A, and rs35431622 A/T showed no significant association with the risk of PCOS. They did not exhibit any influence on the endocrine and obesity-linked parameters in PCOS patients and controls.

\section{Conclusion}

In conclusion, the current study reports three novel SNPs (rs372790354 G/A, rs12998 G/A, and rs35431622 $\mathrm{A} / \mathrm{T}$ ) in the KISS1 gene, among women population of Saudi Arabia and shows a significant influence of rs372790354 G/A on the risk of PCOS. Furthermore, this novel SNP shows a considerable impact on the levels of LH, kisspeptin, and WHR in PCOS women. These findings may improve the understanding of PCOS in regards to its multifactorial etiology, especially those associated with KISS1 gene polymorphisms and their influence on the levels of biochemical and demographic factors. This study has the drawback that it was conducted on only a small number of samples. Hence, further, more extensive studies in different populations are required to confirm this association.

\section{Abbreviations}

BMI: Body mass index; LH: Luteinizing hormone; FSH: Follicle stimulating hormone; UTR: Untranslated region; MAF: Minor allele frequency; SNP: Single nucleotide polymorphisms

\section{Acknowledgements}

The authors express thanks to the staff members of different private hospitals of Makkah, Kingdom of Saudi Arabia, for their active support in the study. The authors also thank the Deanship of Scientific Research at King Saud University, Saudi Arabia, Research Group No RG -1440-077 for providing financial support.

\section{Authors' contributions}

MHD, ASW, MD in conception and design of the study, obtained all the needed chemicals, kits and other requirements. MHD conducted all experimental analysis. $\mathrm{MHD}^{\mathrm{b}}$ contributed in selection of patients, obtained relevant information regarding questionnaire. ASW and MHD conducted the data analysis and interpretation of the data; KA and ASW contributed in preparation and final editing of the manuscript. FSA and LMN were involved in manuscript preparation. All authors read and approved the final manuscript.

\section{Funding}

This present research was funded by Deanship of Scientific Research at King Saud University, Saudi Arabia, Research Group No RG -1440-077.

The funding body played no role in the design of the study and collection, analysis, and interpretation of data and in writing the manuscript.

\section{Availability of data and materials}

The datasets used and/or analysed during the current study are available from the corresponding author on reasonable request.

\section{Ethics approval and consent to participate}

The study was approved by the Ethical Committee of the Institutional Review Board (IRB), Umm Al-Qura University, Makkah, Saudi Arabia (IRB No. 235). Written informed consent was obtained from all participants. 


\section{Consent for publication}

Not applicable.

\section{Competing interests}

The authors declare that they have no competing interest.

\section{Author details}

'Department of Zoology, Female Center for Scientific and Medical Colleges, King Saud University, Riyadh, Saudi Arabia. ${ }^{2}$ Department of Obstetrics \& Gynaecology, Umm-Al-Qura University, Makkah, Saudi Arabia. ${ }^{3}$ Department of Surgery, King Abdulaziz Medical City, National Guard Heath Affairs, Jeddah, Saudi Arabia. ${ }^{4}$ Department of Biotechnology, Integral University, Lucknow, India. Department of Biology, College of Science, Imam Mohammad Ibn Saud Islamic University, Riyadh, Saudi Arabia. ${ }^{6}$ Central Laboratory, Female Center for Scientific and Medical Colleges, King Saud University, Riyadh, Saudi Arabia.

Received: 18 August 2019 Accepted: 22 April 2020

Published online: 07 May 2020

\section{References}

1. March WA, Moore VM, Willson KJ, Phillips DIW, Norman RJ, Davies MJ. The prevalence of polycystic ovary syndrome in a community sample assessed under contrasting diagnostic criteria. Hum Reprod. 2010;25(2):544-51.

2. Hayek SE, Bitar L, Hamdar LH, Mirza FG, Daoud G. Poly cystic ovarian syndrome: an updated overview. Front Physiol. 2016;7:124.

3. Leo VD, Musacchio MC, Cappelli V, Massaro MG, Morgante G, Petraglia F. Genetic, hormonal and metabolic aspects of PCOS: an update. Reprod Biol Endocrinol. 2016;14(38):1-17.

4. Khan MJ, Ullah A, Basit S. Genetic basis of polycystic ovary syndrome (PCOS): current perspectives. Appl Clin Genet. 2019;12:249-60.

5. Umayal B, Chandrasekharan NV, Wijesundera WSS, Wijeyaratne CN. Polycystc ovary syndrome: Genetc Contributons from the hypothalamic-pituitarygonadal Axis. Int Arch Endocrinol Clin Res. 2018;4(013):1-8.

6. Valkenburg O, Uitterlinden AG, Piersma D, Hofman A, Themmen APN, de Jong FH, et al. Genetic polymorphisms of GnRH and gonadotrophic hormone affect the phenotype of polycystic ovary syndrome receptors. Hum Reprod. 2009;24(8):2014-22.

7. Prapas N, Karkanaki A, Prapas I, Kalogiannidis I, Katsikis I, Panidis D. Genetics of polycystic ovary syndrome. Hippokratia. 2009;13(4):216-23.

8. Nejad SZ, Tehrani FR, Vakili AZ. The role of kisspeptin in female reproduction. Int J Endocrinol Metab. 2017;15(3):1-11.

9. Albalawi FS, Daghestani MH, Daghestani MH, Eldali A, Warsy AS. rs4889 polymorphism in KISS1 gene, its effect on polycystic ovary syndrome development and anthropometric and hormonal parameters in Saudi women. J Biomed Sci. 2018;25(50):1-6.

10. Umayal B, Muneeswaran K, Wijesundera WSS, Senanayake A, Chandrasekharan NV, and Wijeyaratne CN. Association of Kiss1 and GPR54 Gene Polymorphisms with Polycystic Ovary Syndrome among Sri Lankan Women. Hindawi BioMed Research International. 2019; Article ID 6235680 $1-10$.

11. Johansson J, Stener-Victorin E. Review Article Polycystic Ovary Syndrome: Effect and Mechanisms of Acupuncture for Ovulation Induction. Hindawi Publishing Corporation Evidence-Based Complementary and Alternative Medicine Volume. 2013: Article ID 762615, 1-16.

12. d'Anglemont TX, Colledge WH. The role of kisspeptin signaling in reproduction. Physiology (Bethesda). 2010;25:207-17.

13. Pinilla L, Aguilar E, Dieguez C, Millar RP, Tena-Sempere M. Kisspeptins and reproduction: physiological roles and regulatory mechanisms. Physiol Rev. 2012;92:1235-316.

14. Jalilian N, Haghnazari L, Rasolinia S. Leptin and body mass index in polycystic ovary syndrome. Indian J Endocrinol Metab. 2016;20(3):324-8.

15. Lu DF, Guo XH. Parameters of obesity in polycystic ovary syndrome. J Rare Dis Res Treat. 2016:2(1):19-22.

16. Zeng Q, He Y, Dong S, Zhao X, Chen Z, Song Z, et al. Optimal cut off values of BMI waist circumference and waist: height ratio for defining obesity in Chinese adults. Br J Nutr. 2014;28(11210):1735-44.

17. Chitme HR, Al Azawi EAK, Al Abri AM, Al Busaidi BM, Salam ZKA, Al Taie MM, et al. Anthropometric and body composition analysis of infertile women with polycystic ovary syndrome. J Taibah Univ Med Sci. 2017:12(2): $139-45$.
18. Lim SS, Davies MJ, Norman RJ, Moran LJ. Overweight, obesity and central obesity in women with polycystic ovary syndrome: a systematic review and meta-analysis. Hum Reprod Update. 2012;18(6):618-37.

19. Rotterdam ESHRE/ASRM-Sponsored PCOS Consensus Workshop Group. Revised 2003 consensus on diagnostic criteria and long-term health risks related to polycystic ovary syndrome. Fertil Steril. 2004;81:19-25.

20. Cao Y, Li Z, Jiang W, Ling Y, Kuang H. Reproductive functions of Kisspeptin/ KISSIR Systems in the Periphery. Reprod Biol Endocrinol. 2019;17:65.

21. Hu KL, Zhao H, Chang HM, Yu Y, Qiao J. Kisspeptin/Kisspeptin Receptor System in the Ovary. Front Endocrinol (Lausanne). 2018;8:365. https://doi. org/10.3389/fendo.2017.00365. eCollection 2017.

22. Trevisan CM, Denise M, Christofolinia Caio P, Barbosaa Keith A, Biancoa CB. Kisspeptin/GPR54 system: what do we know about its role in human reproduction? Cell Physiol Biochem. 2018;49:1259-76.

23. Rosenfield RRL, Ehrmann DA. The pathogenesis of polycystic ovary syndrome (PCOS): the hypothesis of PCOS as functional ovarian Hyperandrogenism. Endocr Rev. 2016;37(5):467-520.

24. Coutinho EA, Kauffman AS. The role of the brain in the pathogenesis and physiology of polycystic ovary syndrome (PCOS). Med Sci (Basel). 2019;7(8): 84.

25. Lin Z, Li W. Evolution of 5' Untranslated Region Length and Gene Expression Reprogramming in Yeasts. Mol Biol Evol. 2012;29(1):81-9.

26. Fan Q, He JF, Wang QR, Cai HB, Sun XG, Zhou XX, et al. Functional polymorphism in the $5^{\prime}-U T R$ of CR2 is associated with susceptibility to nasopharyngeal carcinoma. Endocr Rev. 2016;37(5):467-520.

27. Wang G, Guo $X$, Floros J. Differences in the translation effciency and mRNA stability mediated by 5'-UTR splice variants of human SP-A1 and SP-A2 genes. Am J Physiol Lung Cell Mol Physiol. 2005;289:497-508.

28. Ozay OE, Ozay AC, Acar B, Cagliyan E, Seçil M, Küme T. Role of kisspeptin in polycystic ovary syndrome (PCOS). Gynecol Endocrinol. 2016;32(9):718-22.

29. Yerlikaya E, Akin F, Turgut S, Yaylali G, Topsakal S, Ayada C, et al. Plasma kisspeptin levels in polycystic ovary syndrome. Endocr Abstr. 2013;32:618.

30. Balen AH. Hypersecretion of luteinizing hormone and the polycystic ovary syndrome. Hum Reprod. 1993;8:123-8.

31. Saucedo de la Liata E, Moraga-Sanchez MR, Romeu-Sarrio A, Carmona-Ruiz IO. LH-FSH ratio and polycystic ovary syndrome: a forgotten test? Ginecol Obstet Mex. 2016;84(2):84-94.

32. Chun S. Serum luteinizing hormone level and luteinizing hormone/folliclestimulating hormone ratio but not serum anti-Müllerian hormone level is related to ovarian volume in Korean women with polycystic ovary syndrome. Clin Exp Reprod Med. 2014;41(2):86-91.

33. Malini NA, George KR. Evaluation of different ranges of LH:FSH ratios in polycystic ovarian syndrome (PCOS) - clinical based case control study. Gen Comp Endocrinol. 2018:1(260):51-7.

34. Vrbikova J, Hainer V. Obesity and polycystic ovary syndrome. Obes Facts. 2009;2:26-35.

35. Allahbadia GN, Merchant R. Polycystic ovary syndrome and impact on health. Middle East Fertil J. 2011:16:19-37.

36. Svendsen PF, Ni las L, Nørgaard K, Jensen JE, Madsbad S. Obesity, body composition and metabolic disturbances in polycystic ovary syndrome. Hum Reprod. 2008;23(9):2113-21.

37. Tang R, Ding $X$, Zhu J. Kisspeptin and polycystic ovary syndrome. Front Endocrinol. 2019;298(10):1-7.

\section{Publisher's Note}

Springer Nature remains neutral with regard to jurisdictional claims in published maps and institutional affiliations.

Ready to submit your research? Choose BMC and benefit from:

- fast, convenient online submission

- thorough peer review by experienced researchers in your field

- rapid publication on acceptance

- support for research data, including large and complex data types

- gold Open Access which fosters wider collaboration and increased citations

- maximum visibility for your research: over $100 \mathrm{M}$ website views per year

At $\mathrm{BMC}$, research is always in progress.

Learn more biomedcentral.com/submission 